\title{
Cost of Community-Led Larval Source Management and House Improvement for Malaria Control: A Cost Analysis Within A Cluster-Randomised Trial in A Rural District in Malawi
}

\section{Mphatso Dennis Phiri ( $\nabla$ mdphiri@medcol.mw)}

Malawi-Liverpool-Wellcome Trust Clinical Research Programme https://orcid.org/0000-0002-4072-9715

Robert Sean McCann

University of Maryland School of Medicine

Alinune Nathanael Kabaghe

University of Malawi College of Medicine

Henk van den Berg

Wageningen University Research Centre: Wageningen University \& Research

Tumaini Malenga

African Institute for Policy Development

\section{Steven Gowelo}

University of Malawi, College of Medicine

Tinashe Tizifa

University of Malawi, College of Medicine

Willem Takken

Wageningen University Research Centre: Wageningen University \& Research

Michèle van Vugt

Academic Medical Center: Amsterdam UMC Locatie AMC

\section{Kamija Samuel Phiri}

University of Malawi, College of Medicine

\section{Dianne Janette Terlouw}

Liverpool School of Tropical Medicine

\section{Eve Worrall}

Liverpool School of Tropical Medicine

Research

Keywords: Malaria, cost analysis, house improvement, larval source management, community-led

Posted Date: December 22nd, 2020

DOI: https://doi.org/10.21203/rs.3.rs-131536/v1

License: (c) (i) This work is licensed under a Creative Commons Attribution 4.0 International License. Read Full License 


\section{Abstract}

Background: House improvement (HI) to prevent mosquito house entry, and larval source management (LSM) targeting aquatic mosquito stages to prevent development into adult forms, are promising complementary interventions to current malaria vector control strategies. Lack of evidence on costs and cost-effectiveness of community-led implementation of $\mathrm{HI}$ and LSM has hindered wide scale adoption. This study presents an incremental cost analysis of community-led implementation of $\mathrm{HI}$ and LSM, in a factorial design trial, in addition to standard national malaria control interventions in Chikwawa district, southern Malawi.

Methods: In the trial, LSM comprised draining, filling, and Bacillus thuringiensis israelensis larvicide application, while HI involved closing of eaves and gaps on walls, and screening windows and ventilation spaces with wire mesh. Communities implemented all interventions. Costs were estimated retrospectively using the 'ingredients approach', combining both 'bottom-up' and 'top-down approaches', from the societal perspective. To estimate the cost of independently implementing each intervention arm, resources shared between trial arms (e.g. overheads) were allocated to each consuming arm using proxies developed based on share of resource input quantities consumed. Incremental implementation costs (in 2017 US\$) are presented for HI only, LSM only and HI+LSM arms. In sensitivity analyses, the effect of varying costs of important inputs on estimated costs was explored.

Results: The total economic program costs of community-led HI and LSM implementation was \$626,152. Economic implementation costs of HI, LSM and HI+LSM were estimated as \$27.04, \$25.06 and \$33.44, per person per year, respectively. Staff, transport and labour costs, but not larvicide or screening material, were the major cost drivers across all interventions. Estimated costs were sensitive to changes in staff costs and population covered.

Conclusions: In the context of the trial, the economic costs of community-led HI and LSM implementation were high compared to conventional vector control interventions. Several factors, including the year-round implementation of LSM and low human population density could explain the high costs. The factorial trial design necessitated use of proxies to allocate costs shared between trial arms, which may limit generalisability of estimated costs where different designs are used. Nevertheless, costs may inform planners of future similar intervention packages.

Trial registration: Not applicable. The original trial was registered with The Pan African Clinical Trials Registry on 3 March 2016, trial number PACTR201604001501493.

\section{Background}

Despite significant reductions in cases and deaths between 2000 and 2015, Plasmodium falciparum malaria remains an important global health problem, especially in Africa. This reduction was largely attributed to vector control interventions: insecticide treated nets (ITN) and indoor residual spraying (IRS).[1,2] In addition to ITNs and IRS, intermittent preventative therapy in pregnancy with sulphadoxine-pyrimethamine (IPTp), prompt diagnosis and effective case management with rapid diagnostic tests (RDTs) and artemisinin combination therapy (ACTs) have been key to the recent reduction in burden. [2] However, resistance to insecticides used for ITN and IRS and other challenges have threatened this success: in 2017, 231 million cases were reported compared to 214 million in 2015.[3,4] In addition to insecticide resistance, outdoor mosquito resting and biting behaviour pose a challenge.[5] Use of interventions with different modes of action that target both aquatic and adult mosquito stages could mitigate against these challenges and ensure progress towards current control and elimination targets.[5-8]

Larval source management (LSM) and house improvement $(\mathrm{HI})$ are existing methods of vector control with different modes of action to ITNs and IRS. Both LSM and HI have been shown to reduce malaria transmission and morbidity and therefore could be used as complementary interventions by malaria control programs.[9-12] 
LSM includes any or all of habitat modification, habitat manipulation, biological control, or larviciding; targets aquatic mosquito stages to prevent development into adult forms; and has been shown to reduce malaria transmission and morbidity. $[9,13]$ The World Health Organisation recommends LSM in areas where larval sources are "few, fixed and findable".[13] LSM is a potential complementary option for malaria control in addition to long-lasting ITNs (LLINS) and IRS. Despite LSM's effectiveness, perceptions of high costs and lack of evidence on cost and cost-effectiveness hinder largescale implementation.[14,15] In rural areas with moderate to high malaria transmission there is a gap in evidence on the costs and effectiveness of LSM.[9,10,13]

Similarly, despite historical success and promise for malaria control, $\mathrm{HI}$ interventions, which prevent mosquito house entry, are not prioritised in national malaria control policies.[16] Improved housing is associated with reduced risk of malaria infection.[17-19] A recent systematic review that included six cluster randomised controlled trials of structural house modifications in Africa, only 2 of which have been published to date, concluded that house screening reduces malaria infection and transmission.[20] However, apart from effectiveness, very few studies, albeit with varied house screening designs, reported costs of house improvement interventions.[12,19] No study has included implementation costs of a community-led house improvement or larval source management intervention.

This study presents a trial-based cost analysis conducted to estimate the incremental costs of implementing community-led $\mathrm{HI}$ and LSM, alone or in combination, in addition to standard national malaria control programme (NMCP) interventions. Since the purpose was to estimate the incremental cost of adding these new interventions, including the community engagement programme, to standard practice, we did not analyse the costs of existing NMCP interventions; these interventions are already recognised as being cost-effective. We estimated, from a societal perspective: total and per capita program financial and economic costs of implementing each intervention arm in the Majete Malaria Project LSM/HI trial conducted in Chikwawa district, southern Malawi.[21]

\section{Methods}

\section{Study area}

The MMP LSM/HI trial was part of an operational malaria control project, the Majete Malaria Project (MMP), implemented from 2014 to 2019. MMP was a collaboration between academic institutions (University of Malawi, College of Medicine; Wageningen University and Research; Academic Medical Center, University of Amsterdam; and Liverpool School of Tropical Medicine), non-governmental organisations (African Parks-Majete (AP) and The Hunger Project (THP)) and the Malawi Government Ministry of Health and Chikwawa District Health Office (DHO). The study site and design are reported in detail elsewhere [21]. Briefly, the Majete Wildlife Reserve (MWR) is a wildlife conservation area in Chikwawa district, about 60 kilometres south of Blantyre city, in Malawi. The MMP study area covered an estimated $260 \mathrm{~km}^{2}$, which included three 'focal areas' surrounding the MWR (Figure 1). In 2015, the MMP study area catchment population was estimated at 25,000 people. From April 2015 to April 2016, malaria parasite prevalence in children aged 6-59 months was 33.8\% (95\% confidence interval 30.8-36.9\%). (McCann et al, in press) The main source of income for the communities surrounding MWR is subsistence farming.[22]

In Malawi, malaria transmission is perennial, peaking roughly with the rainy season from November to April.[23] The main malaria vectors are Anopheles gambiae s.s., Anopheles arabiensis and Anopheles funestus.[24] Malaria control relies on long-lasting ITNs (LLINs), IPTp, prompt diagnosis and effective case management with RDTs and ACT artemether lumefantrine, respectively. IRS is currently being implemented in selected districts. Both LSM and house screening were used for malaria control in the 1900s but only LSM, specifically in targeted communities, is included in the 2017-2022 NMCP strategic plan, although it is yet to be implemented to date.[21,23]

The main objective of MMP was to reduce malaria transmission through implementation of community-led interventions including LSM and HI, in addition to standard NMCP interventions.[21] Community engagement was a core objective of the 
project.(15-18) Community volunteers, called health animators, facilitated intensive community engagement workshops throughout the MMP catchment area as well as LSM and HI intervention implementation by community members in their respective villages.[21,25] Health animators facilitated the 'epicentre approach' initiated and managed by THP in communities around MWR. An epicentre is a grouping of villages through which communities are supported to create solutions for their own socio-economic problems, with a view towards self-reliance.[26] The MMP was embedded into this epicentre approach with particular focus on malaria control as an additional means towards socio-economic development. [21]

\section{Trial design}

The MMP LSM/HI trial used a 2x2 factorial design to assess the effect of LSM and $\mathrm{HI}$ on malaria transmission when added to standard national malaria control programme (NMCP) interventions at scale-up for impact targets, over a two-year period. The four trial arms were: 1) NMCP+HI; 2) NMCP+LSM; 3) NMCP+HI+LSM; 4) NMCP only (control arm); hereinafter $\mathrm{HI}, \mathrm{LSM}, \mathrm{HI}+\mathrm{LSM}$ and control arms, respectively. NMCP interventions comprised LLINs; IPTp; and prompt diagnosis and effective case management with RDTs and ACTs, respectively. In addition, as part of the community engagement programme, all trial arms implemented 'malaria village workshops' aimed at increasing awareness and uptake of the NMCP interventions.[25] Each workshop, attended by residents from one or more villages and facilitated by a health animator, involved discussing a malaria-related topic. These workshops started in all MMP catchment area villages one year before the LSM/HI trial and continued throughout the trial. Additional workshops in $\mathrm{HI}$ and/or LSM villages focused on $\mathrm{HI}$ and/or LSM, as per trial arm.[22] No IRS was implemented in the study area during the trial period.[21]

\section{Trial interventions}

MMP project management and technical staff from the academic institutions provided oversight and coordinated logistics relating to intervention implementation. THP and AP facilitated community engagement and intervention uptake. The district health office granted permission and facilitated integration of trial interventions into the existing health system structures. Detailed staff roles are included in Additional File S1. Following discussions with village leaders and trainings, community members implemented all interventions, as below.

LSM consisted of draining, filling and bacterial larviciding (using Bacillus thuringiensis israelensis, abbreviated Bti, AM625 strain, commercial name: VectoBac WDG [Valent Biosciences, Libertyville IL, USA]) of standing water bodies. Following an initial training of trainers, health animators were trained on LSM rationale and methods and cascaded training to other community members. An LSM committee (up to 12 people per one or two villages) was chosen to oversee LSM, including the organization of draining and filling activities. The LSM committees were also directly responsible for Btiapplication. LSM activities occurred all year round: LSM-specific malaria workshops once every 2 weeks; Bti application weekly; the majority of draining and filling was conducted once off initially, with maintenance to prevent standing water as needed thereafter.[25] Bti, protective clothing (face masks and rubber boots) and spraying equipment were provided by the project but the communities conducted all mapping of water bodies, draining, filling and spraying, as well as pre- and post-spray larval sampling as a method for communities to monitor the programme. (see Figure 2) Apart from Bti, imported from the USA, all materials required were locally acquired.

HI entailed structural modification of houses to prevent mosquito entry, specifically closing of eaves using locally available materials used in constructing the houses (mostly brick and mud) and screening holes/spaces used for ventilation, including windows, with wire mesh. Except for wire mesh; heavy-duty scissors for cutting wire mesh; and measuring tape, all other materials, e.g. nails, brick and mud for closing eaves and door frame modifications for implementing HI were provided by communities. (see Figure 2) Similar to LSM, communities were responsible for carrying out all HI activities, with $\mathrm{HI}$ committees providing community-level oversight of activities and monitoring progress.

\section{Costing approach}


This is a retrospective cost analysis from a societal perspective using a combination of 'top-down' and 'bottom-up' approaches.[27] The societal perspective includes both provider (health system) and community costs and is considered the gold standard in economic evaluation. Top-down costing involves allocating programme level costs to component activities while bottom-up costing involves estimating resource use at a micro level and then summing up to estimate total programme level costs. We also used the 'ingredients approach' which involves identifying quantities of inputs (ingredients) used and their unit costs. Analysis was conducted for financial and economic costs.[28] Financial costs are those where money changes hands, whereas economic costs also include non-financial (e.g. donated) resources in addition to financial costs; and thus accounts for all resources consumed.[28,29]

\section{Resource identification and valuation}

Trial protocol and operating manuals were reviewed to populate a list of all activities conducted in each of the three intervention arms (i.e. the control arm was excluded), and the activities were categorised into pre-implementation and implementation phases. Activities were categorised as programmatic, i.e. necessary for routine, intervention implementation, based on field operating manuals. Research activities, defined as those not necessary for routine implementation, were excluded from the analysis. For each programmatic activity, requisite resources ('ingredients') and their quantities were identified from protocols, operating manuals, inventories, activity logbooks, progress reports and socioeconomic sub-studies; and clarified with project staff.[22,25] The proportion of full time employment (\%FTE) was used to estimate staff time spent on trial implementation (as opposed to research or non-trial related activities) based on discussions with relevant staff members; estimated staff cost (\%FTE x salary) were then allocated to the relevant activity. (Additional File S1) Programme management and overhead costs were directly allocated to trial arms according to estimated proportions of use.[29] Unit prices of purchased inputs were valued based on purchase prices extracted from financial records (excluding taxes). Donated resources, and purchased inputs for which unit prices were missing in financial records, were valued using market prices, e.g. local supplier price catalogues for physical items or services; or Malawian minimum wage rates (for non-skilled domestic labour) for community members' time donation, assuming the Ministry of Health would pay communities in programmatic implementation.

All cost data was entered into a Microsoft Excel spreadsheet and summarised into cost categories i.e. staff, training, donated labour, consumables, transport, equipment and malaria workshops, etc. Equipment with a value of more than US\$100 and a useful life of more than one year were defined as capital costs and treated separately in the analysis (below). Thus the final spreadsheet captured quantities and unit costs of each resource input (purchased and donated) used in implementing LSM and HI in the MMP LSM/HI trial.

\section{Cost allocation to trial arms}

Given the factorial trial design, all resources were shared by at least two arms. Thus, suitable proxies were used to allocate the estimated total cost of each input to the respective consuming trial arms. Briefly, 1) purchase costs for capital items which would only be purchased in full assuming each arm were implemented independently, e.g. vehicles, were allocated in full to each arm 2) HI-specific resources required for implementing HI-related activities, e.g. wire mesh, were allocated proportionately to HI-containing arms, i.e. HI only and HI+LSM arms, but not LSM only arm; 3) LSM-specific resources required for implementing LSM-related activities, e.g. larvicide, were proportionately allocated to LSM-containing arms, i.e.

LSM only and HI+LSM arms, but not HI only arm; 4) non-intervention specific resources, e.g. stationery, were allocated proportionately to all arms. Proxies were weighted for the number of households for HI-related items; habitat size for LSMrelated resources; and number of people per arm for non-intervention specific resources. (Figure 3, Additional File S2)

\section{Financial and Economic cost analysis}

Resources were separated into financial (where money changed hands) and non-financial if donated, including pre-existing resources (e.g. project administration offices), community members' time and materials. The financial costing included 
financial inputs only; while the economic costing considered both financial and non-financial costs. For all resource inputs, the original (consumption) currency, i.e. Malawi Kwacha (MWK), Euro or USD, and year was recorded for all costs. Costs were inflated to 2017 values and then converted to equivalent 2017 USD values using year-average International Financial Statistics inflation and exchange rates (https://data.imf.org/regular.aspx?key=61545862), as described in Turner et al.[30] (see Additional File S3) Capital item costs were annualised in the financial costing by dividing the purchase price by the useful life and similarly, with discounting at $3 \%$ in the economic costing, so that only the value of the capital item used during the project lifetime was included in the analysis. For each resource, unit cost was multiplied by quantity consumed to estimate the total financial or economic cost.

The total cost (financial or economic) of each intervention arm is aggregated as total programme cost, total average annual cost, and per household and person per year costs.

The total programme cost for each intervention, i.e. total cost from start to completion of the project, was the sum of allocated costs to that intervention. The total average annual cost is the average of implementation years 1 and 2 costs, which excluded preparatory phase costs. Per household and per person costs are the total average annual costs divided by the number of households in that intervention arm; and the total average annual cost divided by the number of people in the intervention arm, respectively. To aid in planning scale-up, costs are also presented as pre-implementation and implementation phase; by major cost category; and capital and non-capital. Since we aimed to guide implementation scaleup, we allocated shared costs so that each intervention arm had the minimum resources (including administration and village-level resources) required to be implemented independently of the other intervention arms. Consequently, the grand sum of estimated total costs of implementing each arm as standalone exceeds total program costs, but more accurately represents the costs of delivering the intervention arms individually.

For each intervention arm, results are presented in 2017 US\$ for the total, annual, and per person and household financial and economic costs. Costs presented below are economic, unless otherwise specified. Financial and economic costs are presented in Tables 1-3.

\section{Sensitivity analysis}

The robustness to and effect of structural assumptions and parameter uncertainty on estimated total and per person costs was explored in one- and multi-way probabilistic sensitivity analyses using @RISK software ${ }^{\circledR}$ v 7.6 (Palisade Incorporated, USA); an add-in to Microsoft Excel. Cost categories were included in sensitivity analysis if they accounted for $\geq 25 \%$ of total annual average economic costs. We predetermined to explore the effect of changes in population covered as it is a key driver in cost per person calculations.[28] Thus staff costs and population covered were included in sensitivity analysis simulations; all other input categories were excluded. (See Additional File S4) We simulated (100,000 iterations per simulation) the cost per person for each arm when values of staff costs and population covered were varied. For each iteration, input values were randomly sampled from a triangular distribution (defined by minimum, most likely, maximum values) of possible values of staff costs and population covered to calculate the total/per person costs, holding other input costs constant. For population covered, $-/+20 \%$ changes (as minimum and maximum values, respectively) from the trial baseline mean estimates were assumed. For staff costs, the minimum was defined as total staff costs when all salaries were paid using local salary scales without changing the staff structure; i.e. international staff paid as nationals. The trial estimate was taken as maximum value. It was assumed that staff salaries in a trial represent highest possible personnel costs compared to routine implementation where government programme staff are usually used. For both staff and population covered, the trial mean estimates were taken as the 'most likely' value. For each simulation, the cost per person was summarised as a frequency distribution (summarised as mean, 5th and 95th percentile limits) of the 100,000 iteration estimates.

Microsoft Excel ${ }^{\circledR} 2016$ was used for all data management and analysis. 


\section{Results}

In the MMP, both house improvement $(\mathrm{HI})$ and larval source management (LSM) were implemented over a 30-month preimplementation preparatory phase and a 24-month implementation phase, i.e. the "trial period". The period under evaluation thus spans January 2014 to May 2018; the pre-implementation period (up to $30^{\text {th }}$ April 2016) and the trial period (through to $31^{\text {st }}$ May 2018).

The total programme cost of implementing HI, LSM and HI+LSM (pre-implementation phase through to implementation Years 1 and 2) was estimated at $\$ 626,152$.

\section{Housing improvement}

House improvement only arm was implemented in 13 villages, covering 4,568 people from 1,030 households. The total average annual cost was $\$ 123,503$. The average cost per household per year was $\$ 119.91$ while the cost per person was \$27.04. (Table 1)

Staff costs were the main cost driver, accounting for $48.9 \%$ of annual average implementation costs. Transport costs were the second major cost driver: $29.9 \%$ of annual average costs. Screening material and related equipment (i.e. wire mesh, nails and scissors) represented $<2 \%$ of annual average economic costs. Estimated donated time from communities was estimated at \$22,235 in the implementation phase, and represented $9 \%$ of annual average costs. (Table 1) Implementation year 1 accounted for $59 \%$ of total implementation phase costs. Overall, non-capital costs accounted for $79 \%$ of annual average costs.

\section{Larval source management}

Larval source management only was implemented in 24 villages, covering 6,801 people, across 1,520 households. The total average annual total cost of implementing LSM was estimated as $\$ 170,399$. The average cost per household per year was $\$ 112.10$ while the cost per person was $\$ 25.06$. (Table 2)

Staff costs were the main cost driver, accounting for $44.4 \%$ of annual average implementation costs. Transport costs were the second major cost driver: $23.1 \%$ of annual average implementation costs. Bacterial larvicide costs (cost, insurance and freight) represented $3.7 \%$ of annual average implementation costs. Estimated donated time from communities was valued at $\$ 51,528$, representing $15.1 \%$ of annual average implementation costs. Time spent attending village workshops represented half of estimated community costs. Overall, non-capital costs accounted for $85 \%$ of annual average costs in the implementation phase, being similarly distributed between Years 1 and 2 (52 vs 48\%, respectively). (Table 2)

\section{House improvement plus larval source management}

House improvement plus larval source management arm was implemented in 9 villages, covering 4,400 people across 952 households. The total average total cost of implementing HI+LSM was estimated as $\$ 147,152$. The average cost per household per year was $\$ 154.57$ while the cost per person per year was $\$ 33.44$. Staff salary costs were the main cost driver, accounting for $51.5 \%$ of annual average implementation costs. Bacterial larvicide and wire mesh represented $2 \%$ of annual average implementation costs. Transport costs accounted for $26 \%$ of annual average costs in the implementation phase. Estimated donated time from communities was valued at $\$ 27,973$, and represented $9.5 \%$ of annual average implementation costs; of which malaria village workshops represented two-thirds. Overall, non-capital costs represented $82 \%$ of annual average implementation costs, which were similarly distributed across implementation years 1 and 2. (Table 3)

\section{Sensitivity analysis}

In one-way sensitivity analysis, estimated annual average total and per person costs for all intervention arms were sensitive to staff costs and population covered. Assuming that all project staff were paid as nationals (i.e. no expatriate staff) while 
maintaining the same staff structure, and maintaining all other variables, reduced the average annual total and per person cost for each intervention arm by at least $\$ 38,000$ and $\$ 8$, respectively, i.e. $>34 \%$ change in both total and per person costs.

Including staff costs and population covered together in a multi-way sensitivity analysis resulted in an estimated cost per person between \$15-\$34 for all interventions. (see Figure 4 for $\mathrm{HI}$ arm tornado graph, and Additional File S4 for LSM and HI+LSM tornado graphs)

\section{Discussion}

This study estimated the incremental cost of community-led HI and LSM, when implemented alone or in combination, in addition to standard NMCP strategies, within a cluster-randomised trial.

The per person costs of implementing HI, LSM or HI+LSM, i.e. \$27.04, \$25.06 and \$33.44, respectively in 2017 US\$, from a societal perspective were high compared to programs reported elsewhere. In Kenya and Tanzania, three larviciding-only programs cost between US\$ 1.14 and US\$ 3.09 per person per year (adjusted to 2017 US\$).[14] Rahman et al reported tenfold lower than our estimated costs: US\$1.23 per person per year (PPPY) (author-adjusted to 2017 US\$) for a seasonal larviciding program delivered over 2 years in Tanzania.[31] Notably, both studies adopted a provider perspective, i.e. excluded community costs. In The Gambia, a provider-led HI intervention cost \$11.34 PPY (adjusted to USD 2017), and could have increased to $\$ 12.63$ PPPY if communities purchased locally available wire mesh, as opposed to free-of-charge donation.[19]

Several reasons could explain the high costs observed in our study including the all year-round implementation compared to spatial- or temporal-targeting; relatively high (international) staff costs; low population density in the trial area; and/or the considerable community involvement, which included a community engagement program in addition to implementation of LSM and HI. Moreover, the higher economic (compared to financial) costs in this study are due to donated labour costs, reflecting the community-led approach to implementation; and donated office and storage space.

In the MMP LSM/HI trial, interventions were designed to be implemented all year-round. For LSM, the timing and duration of implementation is an important determinant of costs.[13] In the MMP, bacterial larviciding was intended to be repeated weekly, throughout the year. Consequently, bacterial larvicide and application labour costs are high. In Tanzania and Kenya, larviciding was temporally targeted to coincide with the rainy season. Moreover, in MMP, LSM also included draining and filling, which were not included in the Kenya and Tanzania studies. For $\mathrm{HI}$, the timing of the intervention may not significantly impact the estimated cost given that house improvement activities (closing eaves and fixing wire mesh) were a one-off activity, assuming that community time donation was valued equally throughout the year as was the case in this study. For both $\mathrm{HI}$ and LSM, community members attended malaria village workshops at least fortnightly, which increased the estimated economic costs over and above the financial costs as community members were not paid for attending these workshops. Similarly, health animators (including village committee members) spent additional time in community mobilisation activities and intervention-specific planning, monitoring and evaluation activities. However, where providers want to compensate village workshop attendees for their time, the financial costs would be expected to be higher than estimated in this study.

In addition, staff costs were estimated to reflect actual involvement in intervention implementation in the trial (using \%FTE). This decision affected both number and type of staff (national and international) included in the analysis. Similar studies have included international staff, albeit to varying degrees. The effect of excluding some or all of the international experts in the present study on the fidelity of the implementation process is unclear. Consequently, excluding staff based only on cost savings may not be appropriate. Moreover, even for national staff, there might be efficiency gains in routine implementation settings where existing staff assume more responsibilities, reducing project staff costs. This was not explicitly explored in our analysis. Notwithstanding, staff salaries were adjusted for \%FTE time contributions so that, as much as possible, costs 
reflect actual involvement in implementation activities; however, this was imprecise owing to the complex factorial design and possible recall bias when estimating \%FTE.

The study area was a rural setting. For LSM, the choice of urban versus rural setting is particularly important for two reasons. Firstly, with fewer built structures and different land use practices (e.g. more agricultural land use), more and/or larger water bodies suitable for malaria vector larvae may need to be treated in rural villages than urban areas.[13] Consequently, especially for bacterial larvicide and associated application labour costs, the total cost of LSM is likely to be higher in rural versus urban areas, holding other factors constant. Secondly, lower human population densities often associated with rural compared to urban areas, result in smaller denominators in cost per capita calculations; even where size and/or number of water bodies are similar because LSM targets breeding sites in a geographical area rather than the human population per se, compared to e.g. ITN programme costs which should change proportionately with changes in human population.[13] The population density in the MMP catchment area was 96 people/ $\mathrm{km}^{2}$ reflecting the rural nature of the study area (compared to 3,334 people/ $\mathrm{km}^{2}$ for Blantyre City in 2018).[21,32] Though similar in a rural area in Tanzania (47.1 people/ $\mathrm{km}^{2}$ ), population densities in previous seasonal, larviciding-only programmes were much higher:1,082/ $\mathrm{km}^{2}$ in rural Kenyan highlands.[31] In the 1930s, a successful environmental management programme that included larval source management and house screening implemented over a 20-year period in the Zambian Copperbelt covered an average 664 people/ $\mathrm{km}^{2}$.[12] Nonetheless, while per person costs should decrease with increasing human population density covered, the exact form of this relationship is not clear, and may not necessarily be simple linear as it is also affected by the human population-to-larval habitat density ratio.[13]

For $\mathrm{HI}$, relatively fewer built dwelling structures usually associated with rural areas should imply fewer houses to improve, hence lower intervention costs. However, the low population density results in smaller denominators in per capita costs (e.g. 1982 houses covered; on average 4.5 people/household in our study), compared to, say, where few houses are occupied by a large number of people, i.e. large denominators, hence low per capita costs. Moreover, even where there are few houses to improve, the impact of typically large share of programme management costs, may not be completely offset by a low population covered.[33]

Finally, the community-led approach adopted by MMP, compared to predominantly provider-led approaches in other studies, is noteworthy. The benefits of community involvement in the design of malaria interventions have been reviewed elsewhere. To eliminate malaria, communities must take ownership of control interventions.[34-36] This was the rationale for MMP's approach, using existing THP community engagement infrastructure. However, placing the ultimate responsibility of implementing interventions on communities could have impacted our costs in at least two ways. First, the financial costing does not capture community opportunity costs, thus estimated financial costs are lower than economic costs. Secondly, the value placed on communities' labour is likely lower than would be the cost of (semi-) skilled personnel specifically trained in and tasked with LSM and HI activities, hence the estimated cost in this study (using government minimum wage) is lower than would be in the latter scenario. Alternative valuations of communities' donated time, e.g. using skilled personnel wage rates should increase the estimated costs. Necessarily, the present study adopted a societal perspective, in contrast to the cited studies from Kenya, Tanzania and The Gambia where the provider perspective was used.[29] Nevertheless, estimated donated community costs might have been overestimated: malaria village workshops, for example, were planned to be conducted every 2 weeks on average. However, some villages conducted fewer meetings, hence actual costs could have been lower.[22] Furthermore, the costs of pre-existing community engagement infrastructure was included as THP's staff time. However, where such community engagement structures (e.g. the epicentre approach) need to be established first, implementation costs for similar community-led approaches may be higher than reported in this study.

The main strength of this study is the presentation of costs by arm which could guide planners of similar or modified designs in future (cost-)effectiveness studies or routine implementation programmes. Furthermore, to our knowledge, we have reported the first cost analysis of a community-led house improvement intervention. 
However, this cost analysis has several limitations. Due to the factorial design, geographical clustering of interventions and management structure of the trial, cost allocation of shared resources to individual intervention arms was based on proxies rather than precise resource use; therefore our estimates may have been imprecise. Furthermore, our study did not fully consider economies of scale. It is possible that cost per person would be lower where interventions are implemented at large scale (i.e. increasing surface area and people covered), however evidence from scale up of ITN programmes shows that economies of scale occur only at very large programme size, and for IRS programmes, economies of scale are not consistently achieved.[37,38] Similarly, we were unable to quantify and explore the effect of resource capacity utilisation changes, e.g. personnel, vehicles, buildings, etc. It is possible there might be cost savings with increasing capacity utilisation and efficiency of included inputs.[33] Finally, the retrospective data collection approach rendered quantity estimates prone to recall bias, i.e. in project staff interviews.

Our probabilistic sensitivity analysis was limited in several ways. As parameter estimates were not necessarily sampled, and in the absence of published cost estimates, we arbitrarily determined percentage changes and used triangular distributions. This renders our analyses prone to several criticisms. First, the effect of arbitrary percentage changes to parameter estimates is likely to be predictable, driven by magnitude of percentage change, and may not be informative. Therefore, the utility of uncertainty in other important cost categories which we would have otherwise explored, e.g. fixed percentage changes to staff \%FTE, was limited. Second, the changes tested may not necessarily be realistic or likely.[29,33] Furthermore, we did not explore the effect of using different proxies in sensitivity analyses, although these were very important in our study. The proxies used were our best efforts at allocating shared costs in a complex trial, compared to e.g. allocating costs equally across intervention arms which, although we explored, we deemed the approach to be methodologically poor and uninformative. We therefore replicated shared costs across trial arms, assuming that each arm would be implemented independently, as in Mangham-Jefferies et al;[39] although this decision may have overestimated total costs. For economic evaluations alongside factorial trials, there is no consensus how to allocate and analyse shared costs, and how costs (and effects) interact, which ultimately compromises comparability between studies.[40]

Finally, while cost-effectiveness is more informative for resource allocation where multiple options are available, it was not conducted in this study as there was no statistical evidence that the interventions improved epidemiological or entomological outcomes. (McCann et al, in press) Nevertheless, cost analysis is useful for planning interventions in other settings where effectiveness may be different. For the Malawi NMCP, the scenario with all staff costs paid as nationals could be used as a practical working cost estimate for routine implementation of HI, LSM and HI+LSM, with possible cost savings as efficiency and capacity utilisation are maximised, alongside possible increasing economies of scale.

\section{Conclusions}

The costs of implementing community-led HI and LSM, alone or in combination, as implemented in the MMP LSM/HI trial were similar. The estimated cost of implementing each arm can inform future implementation of some or all of the studied interventions. Moreover, since delivering packages of combination interventions is associated with increasing economies of scope, the scenarios and approach presented in this study may be useful for costing future trial and control programme designs; however, the importance of any proxies used will need to be carefully explored. Compared to previous studies, a societal perspective was required to capture the full range of costs of community-led implementation of interventions. This decision may limit comparability. However, as community involvement is important for community ownership and sustainability, future economic evaluations of similarly designed studies or programmes should consider adopting the societal perspective, as in this study.

\section{List Of Abbreviations}

WHO: World Health Organisation; ITN: insecticide-treated net; LSM: larval source management; HI: house screening; ACTs: IRS: indoor residual spraying; Artemisinin combination therapy; RDTs: rapid diagnostic tests; IPTp; Intermittent preventive

Page $10 / 23$ 


\section{Declarations}

\section{Ethics approval and consent to participate}

The study did not involve interviews with or assessment on study participants. The College of Medicine Research and Ethics Committee (COMREC) granted a waiver for this study as no personally identifiable data were used. Furthermore, potentially sensitive project administration information, e.g. positions and salaries, was presented as aggregate categories, so that no individuals could be identified.

\section{Consent for publication}

Not applicable

\section{Availability of data and materials}

The spreadsheet used and analysed during the current study are available from the authors upon reasonable request.

\section{Competing interests}

The authors declare that they have no competing interests.

\section{Funding}

The Majete Malaria Project was generously supported by Dioraphte Foundation, The Netherlands. MP is funded through a Wellcome Trust Master's Fellowship in Public Health and Tropical Medicine (2017-20), Grant number: 205311/Z/16/Z. (Fellowship scheme now called International Master's Fellowship since 2018). EW is co-funded by PIIVEC, Medical Research Council of the UK (MR/P027873/1) through Global Challenges Research Fund, and MIRA, Wellcome Trust UK, Collaborative Award (200222/Z/15/Z). RSM received additional support from an NIH-funded postdoctoral fellowship (T32AI007524). The content is solely the responsibility of the authors and does not necessarily represent the official views of the funders. The decision to draft and submit this manuscript is solely the authors'. None of the funders had any influence over the study design, conduct and manuscript content.

\section{Authors contributions}

MP, EW, RSM, DT and KP conceptualised the study. MP, RSM, and AK collected the data. MP and EW conducted the analysis. MP drafted the manuscript with EW. All authors contributed to manuscript revisions and read and approved the final version.

\section{Acknowledgements}

The authors thank the project management staff of the Majete Malaria Project for providing access to cost data. We are particularly indebted to the project field staff for providing information on the estimates of resource quantities used in this analysis. We are thankful to Zainab Longwe and Asante Kadama for logistical support during data collection. We also thank Professor Bertie Squire for his support and mentorship to MP from securing fellowship through to project completion.

\section{Authors information (optional)}

\section{References}


1. World Health Organization. Global technical strategy for malaria 2016-2030. World Health Organization. Geneva, Switzerland; 2015.

2. Bhatt S, Weiss DJ, Cameron E, Bisanzio D, Mappin B, Dalrymple U, et al. The effect of malaria control on Plasmodium falciparum in Africa between 2000 and 2015. Nature. 2015;526(7572):207-11.

3. World Health Organisation. World Malaria Report 2015. Geneva, Switzerland; 2015.

4. World Health Organisation. World Malaria Report 2017. World Health Organization. Geneva, Switzerland; 2017.

5. Williams YA, Tusting LS, Hocini S, Graves PM, Killeen GF, Kleinschmidt I, et al. Expanding the Vector Control Toolbox for Malaria Elimination: A Systematic Review of the Evidence. In: Advances in Parasitology. Academic Press; 2018. p. 34579.

6. Fillinger U, Kannady K, William G, Vanek MJ, Dongus S, Nyika D, et al. A tool box for operational mosquito larval control: Preliminary results and early lessons from the Urban Malaria Control Programme in Dar es Salaam, Tanzania. Malar J. 2008;7(March 2006):1-25.

7. Govella NJ, Ferguson H. Why Use of Interventions Targeting Outdoor Biting Mosquitoes will be Necessary to Achieve Malaria Elimination. Front Physiol. 2012;3:199.

8. Killeen GF. Characterizing, controlling and eliminating residual malaria transmission. Malar J. 2014;13(1):1-22.

9. Tusting LS, Thwing J, Sinclair D, Fillinger U, Gimnig J, Bonner KE, et al. Mosquito larval source management for controlling malaria. Cochrane Database Syst Rev. 2013;2013(8).

10. Fillinger U, Lindsay SW. Larval source management for malaria control in Africa: Myths and reality. Malar J. 2011;10(1):353.

11. Lindsay SW, Jawara M, Paine K, Pinder M, Walraven GELL, Emerson PM. Changes in house design reduce exposure to malaria mosquitoes. Trop Med Int Heal. 2003;8(6):512-7.

12. Utzinger JJ, Tozan Y, Singer BH. Efficacy and cost-effectiveness of environmental management for malaria control. Trop Med Int Heal. 2001;6(9):677-87.

13. WHO. Larval source management: a supplementary measure for malaria control: an operational manual. Vol. 25 , World Health Organisation. Geneva; 2013.

14. Worrall E, Fillinger U. Large-scale use of mosquito larval source management for malaria control in Africa: A cost analysis. Malar J. 2011;10:1-21.

15. Dambach P, Schleicher M, Stahl HC, Traoré I, Becker N, Kaiser A, et al. Routine implementation costs of larviciding with Bacillus thuringiensis israelensis against malaria vectors in a district in rural Burkina Faso. Malar J. 2016;15(1):1-15.

16. Gimnig JE, Slutsker L. House screening for malaria control. Lancet. 2009;374(9694):954-5.

17. Tusting LS, Ippolito MM, Willey BA, Kleinschmidt I, Dorsey G, Gosling RD, et al. The evidence for improving housing to reduce malaria: A systematic review and meta-analysis. Vol. 14, Malaria Journal. BioMed Central Ltd.; 2015. p. 209.

18. Tusting LS, Bottomley C, Gibson H, Kleinschmidt I, Tatem AJ, Lindsay SW, et al. Housing Improvements and Malaria Risk in Sub-Saharan Africa: A Multi-Country Analysis of Survey Data. von Seidlein L, editor. PLOS Med. 2017;14(2):e1002234.

19. Kirby MJ, Ameh D, Bottomley C, Green C, Jawara M, Milligan PJ, et al. Effect of two different house screening interventions on exposure to malaria vectors and on anaemia in children in The Gambia: a randomised controlled trial. Lancet. 2009;374(9694):998-1009.

20. Furnival-Adams J, Olanga EA, Napier M, Garner P. House modifications for preventing malaria. Cochrane Database Syst Rev. 2020;(10).

21. McCann RS, van den Berg H, Diggle PJ, van Vugt M, Terlouw DJ, Phiri KS, et al. Assessment of the effect of larval source management and house improvement on malaria transmission when added to standard malaria control strategies in southern Malawi: Study protocol for a cluster-randomised controlled trial. BMC Infect Dis. 2017;17(1):639.

Page $12 / 23$ 
22. Malenga T, Kabaghe AN, Manda-Taylor L, Kadama A, Mccann RS, Phiri KS, et al. Malaria control in rural Malawi: implementing peer health education for behaviour change. 2016;

23. Malawi Government Ministry of Health National Malaria Control Programme. Malaria Strategic Plan 2017 - 2022. Lilongwe, Malawi; 2017.

24. Spiers AA, Mzilahowa T, Atkinson D, McCall PJ. The malaria vectors of the Lower Shire valley, Malawi. Malawi Med J. 2002;14(1):4-7.

25. Van Den Berg H, Van Vugt M, Kabaghe AN, Nkalapa M, Kaotcha R, Truwah Z, et al. Community-based malaria control in southern Malawi: A description of experimental interventions of community workshops, house improvement and larval source management. Malar J. 2018;17(1):266.

26. The Hunger Project. Malawi - The Hunger Project US [Internet]. [cited 2020 Sep 15]. Available from: https://thp.org/what-we-do/where-we-work/africa/malawi/

27. Cunnama L, Sinanovic E, Ramma L, Foster N, Berrie L, Stevens W, et al. Using top-down and bottom-up costing approaches in LMICs: The case for using both to assess the incremental costs of new technologies at scale. Heal Econ. 2016;

28. World Health Organisation, Phillips M, Mills AJ, Dye C. Guidelines for Cost-Effectiveness Analysis of Vector Control. Geneva; 1993.

29. Drummond MF, Sculpher MJ, Claxton K, Stoddart GL, Torrance GW, O’Brien B, et al. Methods for the Economic Evaluation of Health Care Programmes. 4th Ed. Oxford: Oxford University Press; 2015.

30. Turner HC, Lauer JA, Tran BX, Teerawattananon Y, Jit M. Adjusting for Inflation and Currency Changes Within Health Economic Studies. Value Heal. 2019;22(9):1026-32.

31. Rahman R, Lesser A, Mboera L, Kramer R. Cost of microbial larviciding for malaria control in rural Tanzania. Trop Med Int Heal. 2016;21(11):1468-75.

32. Malawi National Statistical Office (NSO). 2018 Malawi Population and Housing Main Report. Zomba, Malawi; 2019.

33. WHO. Making choices in health: Guide to cost-effectiveness analysis. Geneva, Switzerland; 2003.

34. Whittaker M, Smith $\mathrm{C}$. Reimagining malaria: five reasons to strengthen community engagement in the lead up to malaria elimination. Vol. 14, Malaria Journal. BioMed Central Ltd.; 2015. p. 410.

35. Atkinson JA, Vallely A, Fitzgerald L, Whittaker M, Tanner M. The architecture and effect of participation: A systematic review of community participation for communicable disease control and elimination. Implications for malaria elimination. Malaria Journal BioMed Central; Dec 4, 2011 p. 225.

36. Baltzell K, Harvard K, Hanley M, Gosling R, Chen I. What is community engagement and how can it drive malaria elimination? Case studies and stakeholder interviews. Malar J. 2019;18(1):245.

37. Wisniewski J, Acosta A, Kolaczinski J, Koenker H, Yukich J. Systematic review and meta-analysis of the cost and costeffectiveness of distributing insecticide-treated nets for the prevention of malaria. Vol. 202, Acta Tropica. Elsevier B.V.; 2020. p. 105229.

38. Abbott M, Johns B. PMI IRS Country Programs: Comparative Cost Analysis, August 11,2011-December 31,2012. Bethesda, MD; 2013. (Africa Indoor Residual Spraying (AIRS) Project, Abt Associates Inc.).

39. Mangham-Jefferies L, Wiseman V, Achonduh OA, Drake TL, Cundill B, Onwujekwe O, et al. Economic evaluation of a cluster randomized trial of interventions to improve health workers' practice in diagnosing and treating uncomplicated malaria in cameroon. Value Heal. 2014;17(8):783-91.

40. Dakin H, Gray A. Economic evaluation of factorial randomised controlled trials: challenges, methods and recommendations. Stat Med. 2017;36(18):2814-30.

41. Kabaghe AN, Chipeta MG, McCann RS, Phiri KS, Van Vugt M, Takken W, et al. Adaptive geostatistical sampling enables efficient identification of malaria hotspots in repeated cross-sectional surveys in rural Malawi. PLoS One.

2017;12(2):1-14.

Page $13 / 23$ 
Tables

Table 1: Financial and economic implementation costs (2017 US\$) of House Improvement (HI) alone

\begin{tabular}{|c|c|c|c|c|c|c|c|c|}
\hline \multirow[t]{2}{*}{ Cost category } & \multicolumn{2}{|c|}{$\begin{array}{l}\text { Pre-implementation } \\
\text { phase }^{\text {a }}\end{array}$} & \multicolumn{2}{|c|}{$\begin{array}{l}\text { Implementation Costs } \\
\text { (Y1) a }\end{array}$} & \multicolumn{2}{|c|}{$\begin{array}{l}\text { Average Annual Costs } \\
\text { a }\end{array}$} & \multicolumn{2}{|c|}{$\begin{array}{l}\text { Percentage of Total } \\
\text { Annual Average }\end{array}$} \\
\hline & Financial & Economic & Financial & Economic & Financial & Economic & $\begin{array}{l}\text { Annual } \\
\text { Financial }\end{array}$ & $\begin{array}{l}\text { Annual } \\
\text { Economic }\end{array}$ \\
\hline \multicolumn{9}{|l|}{ Recurrent Costs } \\
\hline $\begin{array}{l}\text { Staff } \\
\text { (international) }\end{array}$ & 49032 & 49032 & 59069 & 59069 & 46039 & 46039 & 42.6 & 37.3 \\
\hline Staff (national) & 20078 & 20078 & 18354 & 18354 & 14268 & 14268 & 13.2 & 11.6 \\
\hline Training & 12276 & 12276 & 1840 & 1840 & 3738 & 3738 & 3.5 & 3.0 \\
\hline Transport ${ }^{b}$ & 5123 & 5123 & 14890 & 14890 & 12399 & 12399 & 11.5 & 10.0 \\
\hline $\begin{array}{l}\text { Office } \\
\text { consumables } \\
\text { and supplies }\end{array}$ & - & - & 882 & 882 & 836 & 836 & 0.8 & 0.7 \\
\hline $\begin{array}{l}\text { Community } \\
\text { labour } \\
\text { (manual) }^{c}\end{array}$ & - & - & - & 7108 & - & 3554 & 0 & 2.9 \\
\hline $\begin{array}{l}\text { Community } \\
\text { time attending } \\
\text { village } \\
\text { workshops }{ }^{d}\end{array}$ & & 6323 & & 7281 & & 7564 & 0 & 6.1 \\
\hline $\begin{array}{l}\text { IEC and other } \\
\text { community } \\
\text { engagement } \\
\text { activities }^{\text {e }}\end{array}$ & 2361 & 2361 & 1767 & 1767 & 2200 & 2200 & 2.0 & 1.8 \\
\hline $\begin{array}{l}\text { Office space } \\
\text { and storage }\end{array}$ & - & 3190 & - & 4224 & - & 3216 & 0.0 & 2.6 \\
\hline Communication & 1926 & 3484 & 3138 & 4674 & 2321 & 3491 & 2.2 & 2.8 \\
\hline \multicolumn{9}{|l|}{ Capital Costs ${ }^{f}$} \\
\hline Transport ${ }^{b}$ & 24911 & 24911 & 24731 & 24731 & 24580 & 24580 & 22.8 & 19.9 \\
\hline $\begin{array}{l}\text { Computers and } \\
\text { accessories }\end{array}$ & 1987 & 1987 & 154 & 154 & 77 & 77 & 0.1 & 0.1 \\
\hline $\begin{array}{l}\text { Screening wire } \\
\text { mesh and } \\
\text { accessories }\end{array}$ & - & - & 1563 & 1563 & 1540 & 1540 & 1.4 & 1.3 \\
\hline $\begin{array}{l}\text { Sub-Total } \\
\text { Recurrent Costs }\end{array}$ & 90797 & 101868 & 99940 & 120089 & 81802 & 97306 & 75.7 & 78.8 \\
\hline $\begin{array}{l}\text { Sub-Total } \\
\text { Capital Costs }\end{array}$ & 26898 & 26898 & 26295 & 26295 & 26197 & 26197 & 24.3 & 21.2 \\
\hline Total Costs & 117695 & 128766 & 126388 & 146537 & 107999 & 123503 & 100.0 & 100.0 \\
\hline Cost per Person & & & & & 23.64 & 27.04 & & \\
\hline
\end{tabular}


a Pre-implementation phase: Jan 2014-April 2016.Y1=Year 1 (May 2016-April 2017). Year 2=May 2017-May 2018 (cost not shown). Implementation phase=Year 1 and Year 2. Annual average costs=(Year 1+Year 2)/2.

b Transport: Recurrent transport costs include vehicle operating costs only (fuel, insurance, maintenance and repairs). Capital transport costs include vehicle purchase costs only.

${ }^{\mathrm{c}}$ Manual labour donated by community members towards $\mathrm{HI}$ activities: closing eaves, gaps in walls, and fixing wire mesh, etc, valued using Malawi government minimum wage rate

d e Community time attending village workshops (person-hours spent per workshop), valued using Malawi government minimum wage rate

e IEC=Information, Education and Communication, including costs of printing and translation of educational material, implementation guides/manuals, etc. Other community engagement activities include community members labour towards disseminating messages about interventions (e.g. village 'criers' to inform community members of upcoming meetings

${ }^{f}$ Capital costs: Costs for items with a useful life of $>1$ year and replacement value of $>\$ 100$.

Table 2: Financial and economic implementation costs (2017 US\$) of Larval Source Management (LSM) alone 


\begin{tabular}{|c|c|c|c|c|c|c|c|c|}
\hline \multirow[t]{2}{*}{ Cost category } & \multicolumn{2}{|c|}{$\begin{array}{l}\text { Pre-implementation } \\
\text { phase }^{\text {a }}\end{array}$} & \multicolumn{2}{|c|}{$\begin{array}{l}\text { Implementation Costs } \\
(\mathrm{Y} 1)^{a}\end{array}$} & \multicolumn{2}{|c|}{$\begin{array}{l}\text { Average Annual Costs } \\
\text { a }\end{array}$} & \multicolumn{2}{|c|}{$\begin{array}{l}\text { Percentage of Total } \\
\text { Annual Average }\end{array}$} \\
\hline & Financial & Economic & Financial & Economic & Financial & Economic & $\begin{array}{l}\text { Annual } \\
\text { Financial }\end{array}$ & $\begin{array}{l}\text { Annual } \\
\text { Economic }\end{array}$ \\
\hline \multicolumn{9}{|l|}{ Recurrent Costs } \\
\hline $\begin{array}{l}\text { Staff } \\
\text { (international) }\end{array}$ & 29419 & 29419 & 59069 & 59069 & 57829 & 57829 & 41.6 & 33.9 \\
\hline Staff (national) & 12047 & 12047 & 18370 & 18370 & 17910 & 17910 & 12.9 & 10.5 \\
\hline Training & 15499 & 15499 & 11645 & 11645 & 8919 & 8919 & 6.4 & 5.2 \\
\hline Transport $^{\mathrm{b}}$ & 5469 & 5469 & 15643 & 15643 & 13996 & 13996 & 10.1 & 8.2 \\
\hline $\begin{array}{l}\text { Bacterial } \\
\text { larvicide (Bti, } \\
\text { CIF) }{ }^{c}\end{array}$ & - & - & 5883 & 5883 & 6244 & 6244 & 4.5 & 3.7 \\
\hline $\begin{array}{l}\text { Office } \\
\text { consumables } \\
\text { and sundries }\end{array}$ & - & - & 1313 & 1313 & 1245 & 1245 & 0.9 & 0.7 \\
\hline $\begin{array}{l}\text { Community } \\
\text { labour } \\
\text { (manual) d }\end{array}$ & - & & - & 12492 & - & 13085 & 0.0 & 7.7 \\
\hline $\begin{array}{l}\text { Community } \\
\text { time attending } \\
\text { village } \\
\text { workshops }^{\mathrm{e}}\end{array}$ & & 9393 & - & 12212 & - & 12679 & 0.0 & 7.4 \\
\hline $\begin{array}{l}\text { IEC and other } \\
\text { community } \\
\text { engagement } \\
\text { activities }^{f}\end{array}$ & 3074 & 3074 & 2631 & 2631 & 3275 & 3275 & 2.4 & 1.9 \\
\hline $\begin{array}{l}\text { Office space } \\
\text { and storage }\end{array}$ & - & 1914 & - & 4224 & - & 4005 & 0.0 & 2.4 \\
\hline Communication & 1156 & 2090 & 3138 & 4674 & 2858 & 4315 & 2.1 & 2.5 \\
\hline $\begin{array}{l}\text { Small } \\
\text { equipment } \mathrm{g}\end{array}$ & - & - & 850 & 850 & 474 & 474 & 0.3 & 0.3 \\
\hline \multicolumn{9}{|l|}{ Capital Costs ${ }^{f}$} \\
\hline Transport $^{\mathrm{b}}$ & 25659 & 25659 & 25503 & 25503 & 25312 & 25312 & 18.2 & 14.9 \\
\hline $\begin{array}{l}\text { Computers and } \\
\text { accessories }\end{array}$ & 1987 & 1987 & 154 & 154 & 77 & 77 & 0.1 & 0.1 \\
\hline $\begin{array}{l}\text { Personal } \\
\text { protective } \\
\text { equipment for } \\
\text { spraying }\end{array}$ & - & - & 974 & 974 & 1035 & 1035 & 0.7 & 0.6 \\
\hline $\begin{array}{l}\text { Sub-Total } \\
\text { Recurrent Costs }\end{array}$ & 66664 & 78906 & 118542 & 149006 & 112750 & 143976 & 81.0 & 84.5 \\
\hline $\begin{array}{l}\text { Sub-Total } \\
\text { Capital Costs }\end{array}$ & 27646 & 27646 & 26630 & 26630 & 26423 & 26423 & 19.0 & 15.5 \\
\hline Total Costs & 94310 & 106553 & 145172 & 175636 & 139173 & 170399 & 100 & 100 \\
\hline
\end{tabular}


a Pre-implementation phase: Jan 2014-April 2016.Y1=Year 1 (May 2016-April 2017). Year 2=May 2017-May 2018 (cost not shown). Implementation phase=Year 1 and Year 2. Annual average costs=(Year $1+$ Year 2)/2.

b Transport: Recurrent transport costs include vehicle operating costs only (fuel, insurance, maintenance and repairs). Capital transport costs include vehicle purchase costs only.

${ }^{\mathrm{c}}$ Cost and insurance and freight for bacterial larvicide (Bti: Bacillus thuringiensis israelensis, AM625 strain, commercial name: VectoBac WDG [Valent Biosciences, Libertyville IL, USA]). Shipped from the USA to Malawi

${ }^{\mathrm{d}}$ Manual labour donated by community members towards LSM activities: draining, filling and bacterial larvicide application to water bodies; mapping water bodies; and monitoring; etc valued using Malawi government minimum wage rate

${ }^{\text {e }}$ Community time attending village workshops (person-hours spent per workshop), valued using Malawi government minimum wage rate.

${ }^{d} \mathrm{IEC}=$ Information, Education and Communication, including costs of printing and translation of educational material, implementation guides/manuals, etc. Other community engagement activities include community members labour towards disseminating messages about interventions (e.g. village 'criers' to inform community members of upcoming meetings

e Other small equipment not meeting threshold for "capital" items (e.g. (e.g. buckets for drawing water, hoes, shovels donated from communities). See (f)

${ }^{f}$ Capital costs: Costs for items with a useful life of $>1$ year and replacement value of $>\$ 100$.

Table 3: Financial and economic implementation costs (2017 US\$) of House Improvement and Larval Source Management combined 


\begin{tabular}{|c|c|c|c|c|c|c|c|c|}
\hline \multirow[t]{2}{*}{ Cost category } & \multicolumn{2}{|c|}{$\begin{array}{l}\text { Pre-implementation } \\
\text { phase }^{\text {a }}\end{array}$} & \multicolumn{2}{|c|}{$\begin{array}{l}\text { Implementation Costs } \\
(\mathrm{Y} 1)^{\mathrm{a}}\end{array}$} & \multicolumn{2}{|c|}{$\begin{array}{l}\text { Average Annual Costs } \\
\text { a }\end{array}$} & \multicolumn{2}{|c|}{$\begin{array}{l}\text { Percentage of Total } \\
\text { Annual Average }\end{array}$} \\
\hline & Financial & Economic & Financial & Economic & Financial & Economic & $\begin{array}{l}\text { Annual } \\
\text { Financial }\end{array}$ & $\begin{array}{l}\text { Annual } \\
\text { Economic }\end{array}$ \\
\hline \multicolumn{9}{|l|}{ Recurrent Costs } \\
\hline $\begin{array}{l}\text { Staff } \\
\text { (international) }\end{array}$ & 49032 & 49,032 & 59069 & 59069 & 57829 & 57829 & 45.3 & 39.3 \\
\hline Staff (national) & 20078 & 20,078 & 18353 & 18353 & 17894 & 17894 & 14.0 & 12.2 \\
\hline Training & 11863 & 11,863 & 4330 & 4330 & 4953 & 4953 & 3.9 & 3.4 \\
\hline Transport & 5097 & 5,097 & 14917 & 14917 & 13462 & 13462 & 10.5 & 9.2 \\
\hline $\begin{array}{l}\text { Bacterial } \\
\text { larvicide (Bti, } \\
\text { CIF) }\end{array}$ & - & - & 1573 & 1573 & 1669 & 1669 & 1.3 & 1.1 \\
\hline $\begin{array}{l}\text { Office } \\
\text { consumables } \\
\text { and supplies }\end{array}$ & - & - & 882 & 882 & 822 & 822 & 0.6 & 0.6 \\
\hline $\begin{array}{l}\text { Community } \\
\text { labour } \\
\text { (manual) }^{d}\end{array}$ & - & - & - & 8383 & - & 6020 & 0.0 & 4.1 \\
\hline $\begin{array}{l}\text { Community } \\
\text { time attending } \\
\text { village } \\
\text { workshops e }\end{array}$ & - & 6,087 & & 7669 & - & 7967 & 0.0 & 5.4 \\
\hline $\begin{array}{l}\text { IEC and other } \\
\text { community } \\
\text { engagement } \\
\text { activities }^{d}\end{array}$ & 2315 & 2,315 & 1702 & 1702 & 2119 & 2119 & 1.7 & 1.4 \\
\hline $\begin{array}{l}\text { Office space } \\
\text { and storage }\end{array}$ & - & 3,190 & - & 4224 & - & 4005 & 0.0 & 2.7 \\
\hline Communication & 1926 & 3,484 & 3138 & 4674 & 2858 & 4315 & 2.2 & 2.9 \\
\hline $\begin{array}{l}\text { Small } \\
\text { equipment e } \\
\text { (e.g. buckets for } \\
\text { drawing water) }\end{array}$ & - & - & 227 & 227 & 127 & 127 & 0.1 & 0.1 \\
\hline \multicolumn{9}{|l|}{ Capital Costs ${ }^{f}$} \\
\hline Transport & 24854 & 24,854 & 24673 & 24673 & 24525 & 24525 & 19.2 & 16.7 \\
\hline $\begin{array}{l}\text { Computers and } \\
\text { accessories }\end{array}$ & 1987 & 1,987 & 154 & 154 & 77 & 77 & 0.1 & 0.1 \\
\hline $\begin{array}{l}\text { Screening } \\
\text { materials and } \\
\text { accessories }\end{array}$ & - & - & 1370 & 1370 & 1369 & 1369 & 1.1 & 0.9 \\
\hline $\begin{array}{l}\text { Sub-Total } \\
\text { Recurrent Costs }\end{array}$ & 90313 & 101,147 & 104192 & 126003 & 101732 & 121181 & 79.7 & 82.4 \\
\hline $\begin{array}{l}\text { Sub-Total } \\
\text { Capital Costs }\end{array}$ & 26841 & 26,841 & 26197 & 26197 & 25971 & 25971 & 20.3 & 17.7 \\
\hline Total Costs & 117154 & 127,989 & 130388 & $\begin{array}{l}152200 \\
\text { ge } 18 / 23\end{array}$ & 127704 & 147152 & 100.00 & 100.00 \\
\hline
\end{tabular}


a Pre-implementation phase: Jan 2014-April 2016.Y1=Year 1 (May 2016-April 2017). Year 2=May 2017-May 2018 (cost not shown). Implementation phase=Year 1 and Year 2. Annual average costs=(Year $1+$ Year 2)/2.

${ }^{b}$ Transport: Recurrent transport costs include vehicle operating costs only (fuel, insurance, maintenance and repairs). Capital transport costs include vehicle purchase costs only.

${ }^{\mathrm{c}}$ Cost and insurance and freight for bacterial larvicide (Bti: Bacillus thuringiensis israelensis, AM625 strain, commercial name: VectoBac WDG [Valent Biosciences, Libertyville IL, USA]). Shipped from the USA to Malawi

d Manual labour donated by community members towards HI and LSM activities: closing eaves, gaps in walls, and fixing wire mesh; draining, filling and bacterial larvicide application to water bodies; mapping water bodies; and monitoring;

${ }^{\text {e }}$ Community time attending village workshops (person-hours spent per workshop), valued using Malawi government minimum wage rate.

${ }^{d}$ IEC=Information, Education and Communication, including costs of printing and translation of educational material, implementation guides/manuals, etc. Other community engagement activities include community members labour towards disseminating messages about interventions (e.g. village 'criers' to inform community members of upcoming meetings

e Other small equipment not meeting threshold for "capital" items (e.g. (e.g. buckets for drawing water, hoes, shovels donated from communities). See (f)

${ }^{f}$ Capital costs: Costs for items with a useful life of $>1$ year and replacement value of $>\$ 100$.

\section{Figures}




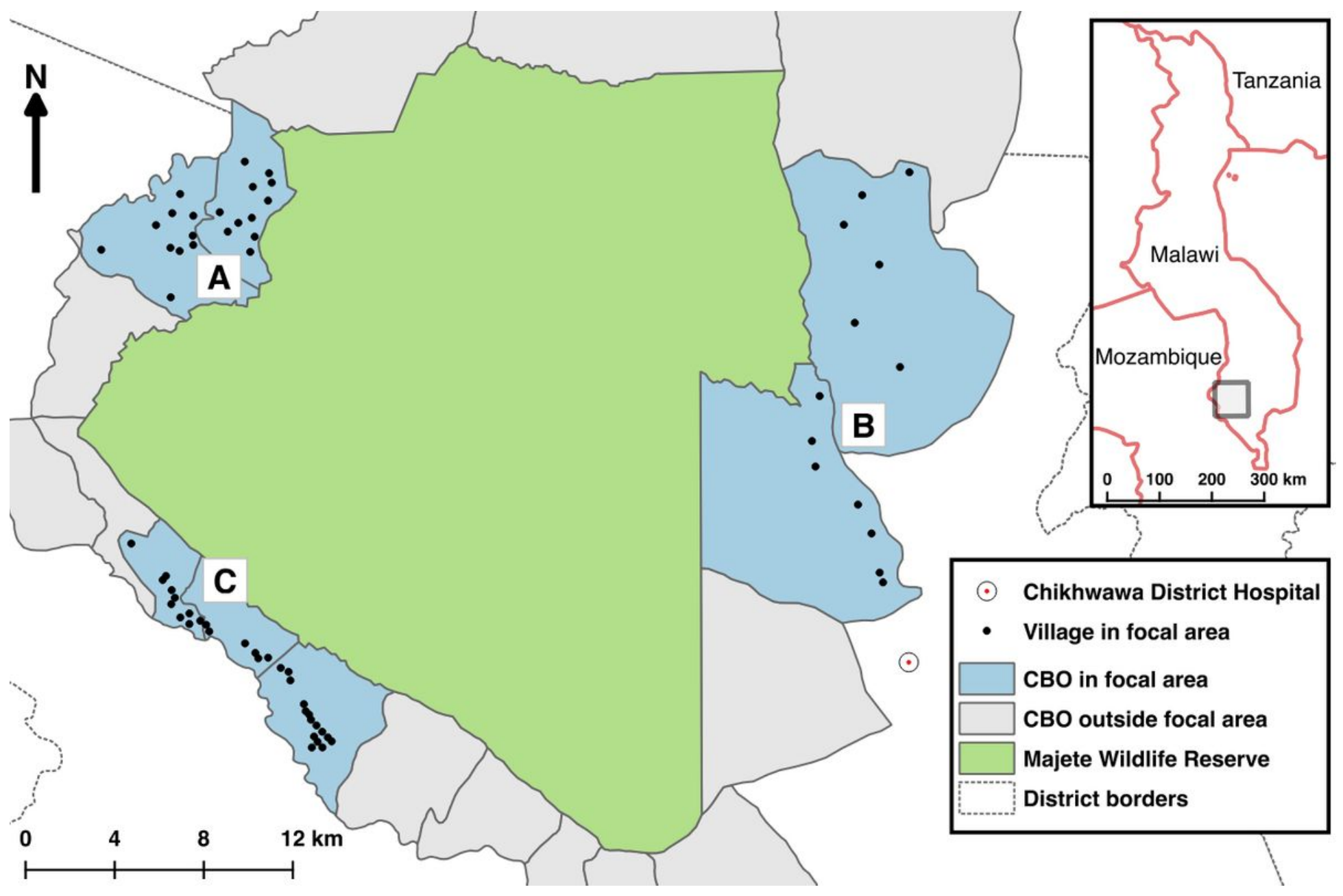

Figure 1

Map of Majete Wildlife Reserve, showing the Majete Malaria Project (MMP) study site. A B and C denote 'focal areas' in which the trial was implemented. Focal areas were a group a villages selected to coincide with The Hunger Project epicentres - pre-existing organisational units of socio economic development and community engagement - within which the MMP was implemented. The main project field station from which field staff operated and coordinated field activities (including planning and oversight, storage of project items, etc) was located close to Focal area B. (Adapted with permission from Kabaghe et al, 2017).[41] Note: The designations employed and the presentation of the material on this map do not imply the expression of any opinion whatsoever on the part of Research Square concerning the legal status of any country, territory, city or area or of its authorities, or concerning the delimitation of its frontiers or boundaries. This map has been provided by the authors. 


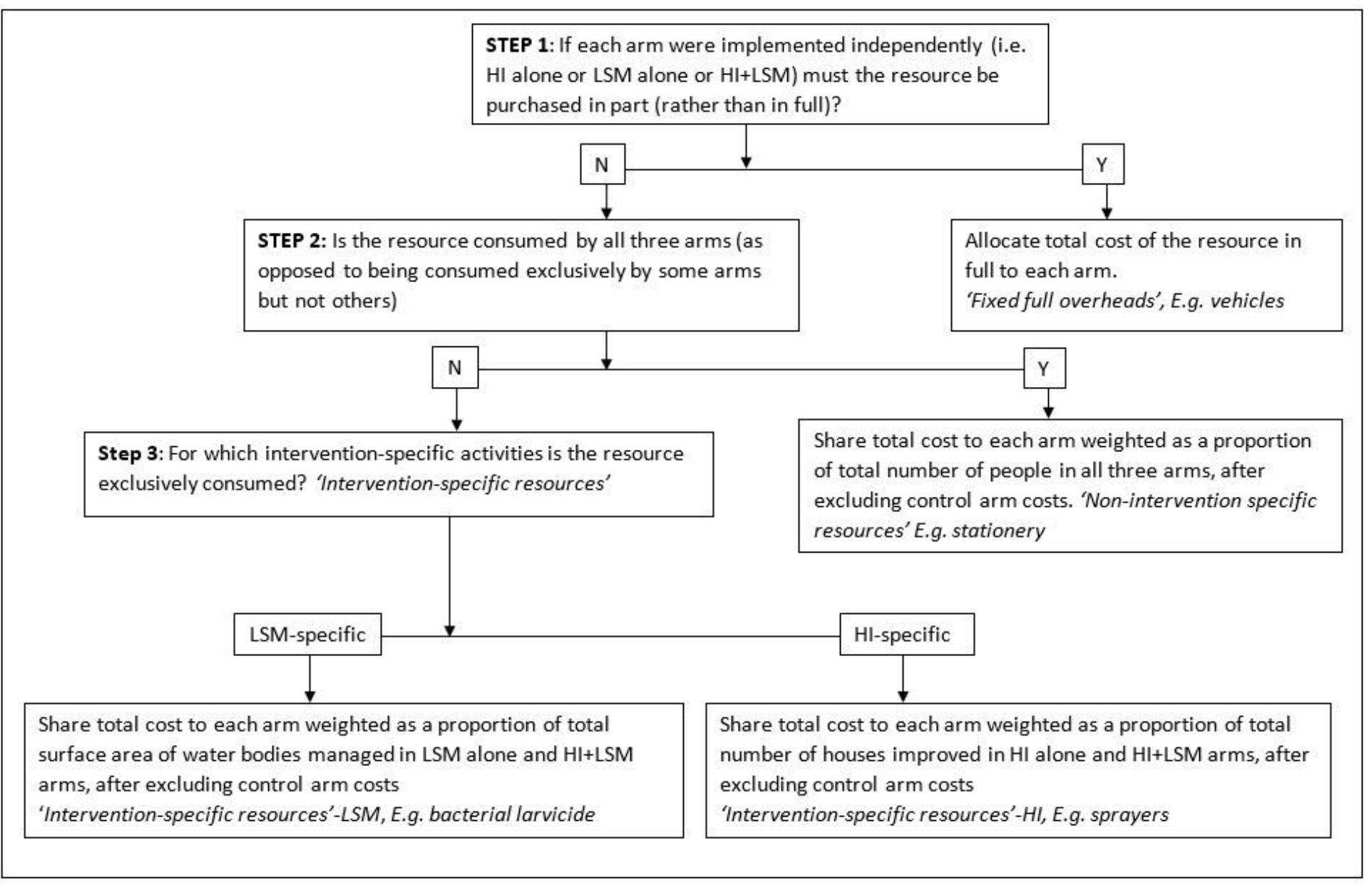

\section{Figure 2}

House improvement (top panels) and larval source management (bottom panels). A: pre-intervention; B: closed gable; C: screened 'windows'; D: former water body filled with soil; E: drainage passage created to prevent standing water; F: trained LSM committee member applying Bacillus thuringiensis israelensis to water bodies. Reprinted with permission from van den Berg et al, 2018.[25] 

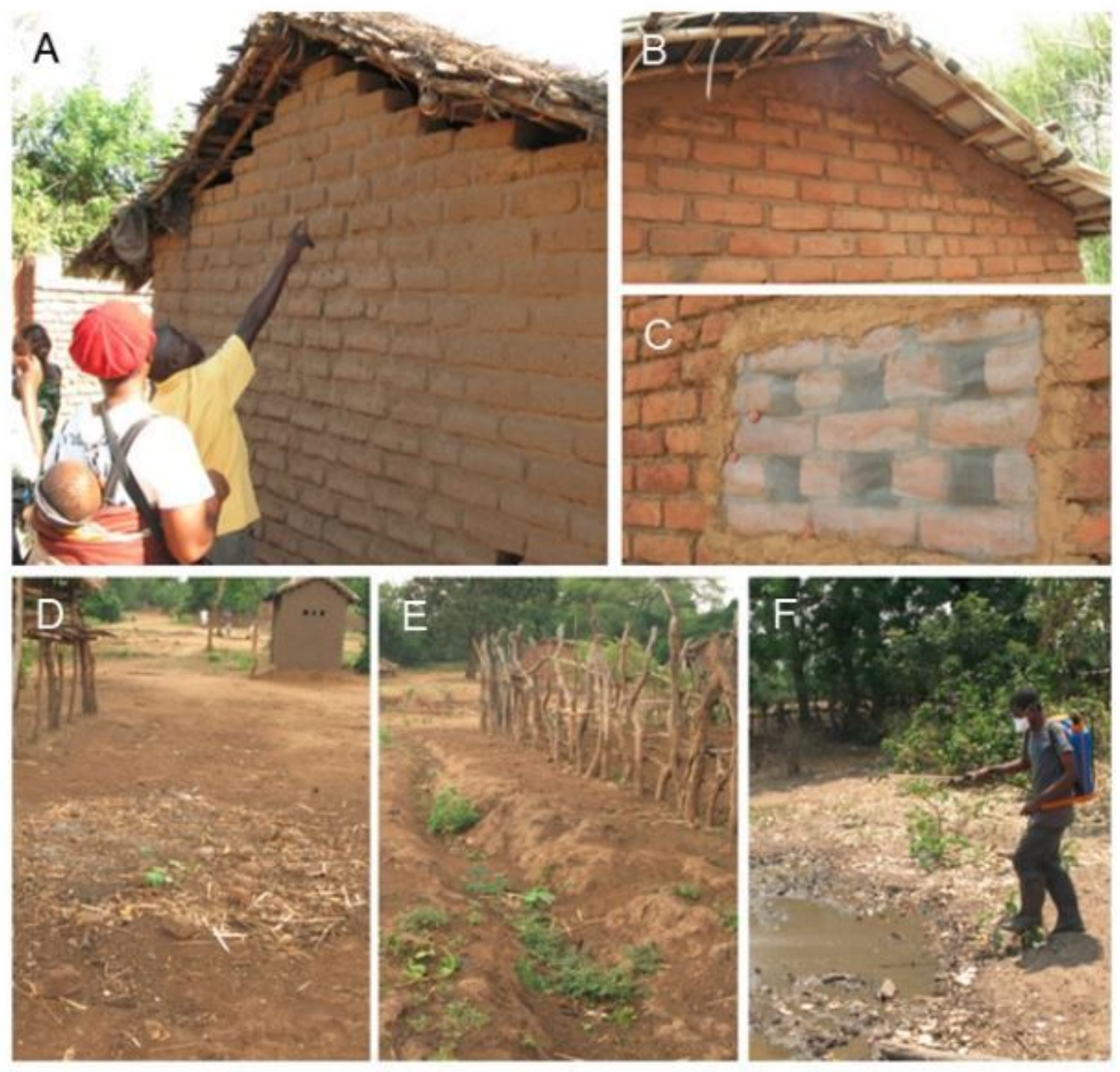

\section{Figure 3}

Algorithm showing decisions taken when sharing costs of shared resources to trial intervention arms. Note: due to the factorial design of the trial, all resources were shared between at least two trial arms. 


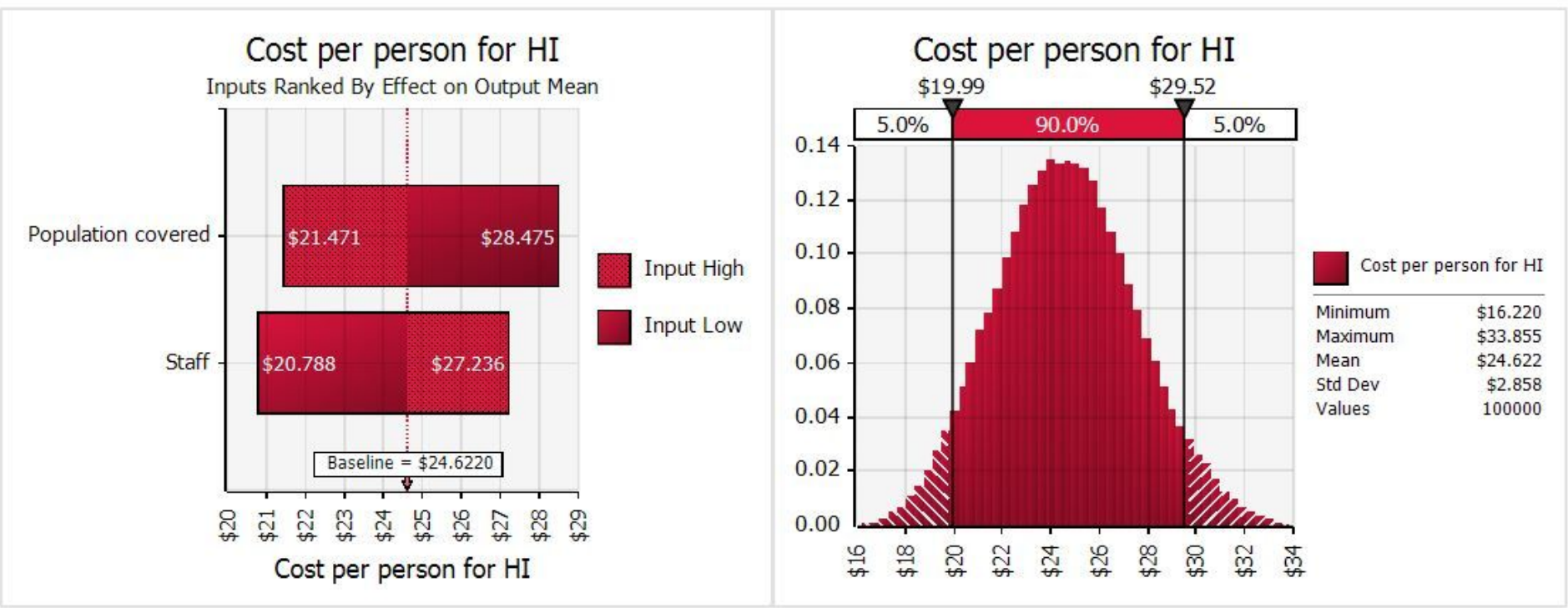

\section{Figure 4}

Tornado graph of sensitivity analysis for mean cost per person for house improvement alone arm. The simulated effect of changes in staff costs and population covered on estimated mean cost per person. The left panel shows the change in cost per person from the baseline, i.e. trial mean estimate, when staff costs and population covered are varied. The lighter (dotted) shade of the bar corresponds to increasing input values. The darker (solid fill) shade corresponds to decreasing input values. For both LSM and HI+LSM, the cost per person increases with increasing staff costs; and reduces with increasing population covered; and vice versa. The right panels show the corresponding frequency distribution of simulated estimates of cost per person. The area bound by the black vertical line represents the upper limits of the 5th and 95th percentiles (i.e. $90 \%$ uncertainty interval) of simulated cost per person estimates of HI: US\$19.99-29.52 The minimum, most likely and maximum values, respectively, used for the distributions were: Staff cost: \$ 43798; \$ 120616; \$ 120616 Population covered: $3654 ; 4568 ; 5482$ Note: The designations employed and the presentation of the material on this map do not imply the expression of any opinion whatsoever on the part of Research Square concerning the legal status of any country, territory, city or area or of its authorities, or concerning the delimitation of its frontiers or boundaries. This map has been provided by the authors.

\section{Supplementary Files}

This is a list of supplementary files associated with this preprint. Click to download.

- PhiriMDAdditionalFileS1.docx

- PhiriMDAdditionalFileS2.docx

- PhiriMDAdditionalFileS3.docx

- PhiriMDAdditionalFileS4.docx 